\title{
Lidocaine can reduce the pain of intra-osseous fluid infusion
}

\author{
Jonathan Ilicki ${ }^{*}$ and Jesper Scholander \\ See related research by Petitpas et al., http://ccforum.biomedcentral.com/articles/10.1186/s13054-016-1277-6
}

We read the review by Petitpal et al on intra-osseous access (IOA) in adults with great interest [1]. The review was concise, and offers a comprehensive overview of IOA. However, we disagree with one key aspect.

The authors state that: "Despite a lack of evidencebased medicine, administration of lidocaine ... has been proposed in conscious patients". Two studies are cited to support that IOA is painful, and that it is unclear if lidocaine decreases pain associated with IOA. The first study is a case series $(n=26)$ which does not state if lidocaine was given and at what dose [2]. In the second study, 22 conscious patients received an intra-osseous (IO) needle. Of the 12 that received local anaesthesia, four were pain-free whereas the remainder experienced some pain. However, as the study did not report pain scores it is unclear but possible that the group with lidocaine experienced less pain [3].

A short-cut review from 2013 assessed the evidence for the use of local anaesthetics in IOA [4]. The review identified one conference abstract and one open-label study. Both were small $(n=10)$, open-label and manufacturersponsored, and compared different doses of lidocaine and insertion sites with regards to pain. Based on those findings the review concluded that injecting lidocaine both before and after flushing an IO needle is an effective method of reducing the pain of fluid infusion.

In clinical practice, using lidocaine for IO insertion in conscious patients takes little time and is unlikely to cause harm. We agree with the authors that there is a paucity of evidence, but the little research that does exist supports administering lidocaine in order to prevent pain.

\begin{abstract}
Abbreviations
IO, intra-osseous; IOA, intra-osseous access
\end{abstract}

Acknowledgements

Not applicable.

Availability of data and materials

All data supporting our findings is available through PubMed.

\section{Authors' contributions}

$J I$ wrote the letter. JS proofread and edited the letter. Both authors read and approved the final manuscript.

\section{Competing interests}

The authors have performed a non-commissioned conference lecture on IOA, where JI demonstrated intra-osseous needle insertion on JS. The authors received equipment to practice $\mathrm{IO}$ insertion from a manufacturer prior to the lecture.

Published online: 20 June 2016

\section{References}

1. Petitpas F, Guenezan J, Vendeuvre T, Scepi M, Oriot D, Mimoz O. Use of intra-osseous access in adults: a systematic review. Crit Care. 2016;20(1):102.

2. Cooper BR, Mahoney PF, Hodgetts TJ, Mellor A. Intra-osseous access (EZ-IO) for resuscitation: UK military combat experience. J R Army Med Corps. 2007;153(4):314-6.

3. Schalk R, Schweigkofler U, Lotz G, Zacharowski K, Latasch L, Byhahn C. Efficacy of the EZ-IO needle driver for out-of-hospital intraosseous access - a preliminary, observational, multicenter study. Scand J Trauma Resusc Emerg Med. 2011;19:65.

4. Stewart M. Towards evidence-based emergency medicine: Best BETs from the Manchester Royal Infirmary. BET 1: local anaesthetics in intraosseous access. Emerg Med J. 2013;30(5):423-4.

\footnotetext{
* Correspondence: j.ilicki@gmail.com

Department of Emergency Medicine, Karolinska University Hospital, 17176 Solna, Sweden
}

(c) 2016 The Author(s). Open Access This article is distributed under the terms of the Creative Commons Attribution 4.0 International License (http://creativecommons.org/licenses/by/4.0/), which permits unrestricted use, distribution, and reproduction in any medium, provided you give appropriate credit to the original author(s) and the source, provide a link to the Creative Commons license, and indicate if changes were made. The Creative Commons Public Domain Dedication waiver (http://creativecommons.org/publicdomain/zero/1.0/) applies to the data made available in this article, unless otherwise stated. 